\title{
META ANALISIS : HUBUNGAN KREATIVITAS DAN ACHIEVEMENT
}

\author{
Diajeng Retno Kinanti Putri', Ahman, Eka Sakti Yudha ${ }^{2}$ \\ Jurusan Bimbingan dan Konseling, Fakultas Ilmu Pendidikan, Universitas Pendidikan Indonesia \\ Email: diajengretnokinantiputri@upi.edu
}

\begin{abstract}
This research is meta-analysis research that tries to collect several correlational studies related to Creativity and Achievement or academic achievement through several indexed international journals. The purpose of this study was to see how creative ability influences students' academic achievement at the level of education from elementary school to university level. This study used correlational statistical techniques and found an $r$-value of 0.305 and a p-value of $p=<.001$. From the results above that $p$ value $<0.05$, it can be concluded that the results of the meta-analysis failed to reject the null hypothesis (HO). However, with a value of $r=0.305$, it can be said that this has a weak correlation or it can be concluded that creativity and academic achievement are not significantly correlated. This is because there are several influencing factors, such as age, teaching methods, and assignments.
\end{abstract}

Keywords : Meta Analysis, Creativity, Achievement

\begin{abstract}
ABSTRAK
Penelitian ini merupakan penelitian meta analisis yang mencoba untuk mengumpulkan beberapa penelitian korelasional yang berkaitan dengan Kreativitas dan Achievement atau prestasi akademik melalui beberapa jurnal internasional yang sudah terindeks. Tujuan penelitian ini adalah melihat seberapa pengaruh kemampuan kreatif terhadap prestasi akademik siswa pada tingkat pendidikan dari jenjang sekolah dasar hingga perguruan tinggi. Penelitian ini menggunakan teknik statistik korelasional dan menemukan nilai $r$ sebesar 0,305 dan nilai $p$ sebesar $p=<.001$. Dari hasil di atas bahwasannya $p$ value < 0,05 dapat disimpulkan bahwa hasil meta analisis gagal menolak hipotesis nol (HO). Namun dengan nilai $r=0.305$ dapat dikatakan bahwa ini memiliki korelasi yang lemah atau dapat disimpulkan bahwa kreativitas dan prestasi akademik tidak berkorelasi secara signifikan. Hal ini disebabkan karena ada beberapa faktor yang mempengatuhi, seperti usia, metode pengajaran dan penugasan.
\end{abstract}

Kata Kunci : Meta Analisis, Kreativitas, Achievement

\section{PENDAHULUAN}

Pendidikan dapat mempengaruhi kreativitas siswa (Runco, 2007). Sesungguhnya di dalam sekolah merupakan salah satu wadah yang dapat mendukung anak agar dapat mempraktikkan pemikiran kreatif, dukungan untuk perilaku kreatif, dan pemodelan serta penilaian pemikiran kreatif dan perilaku kreatif. Kreativitas bersifat individualis, sebab kreativitas satu dan lain anak berbeda (Runco, 2007). Namun yang selama ini terjadi pengembangan kurikulum hanya difokuskan pada kelompok, kurang mendukung kreativitas-kreativitas yang dimiliki oleh masingmaisng individu. Dalam artian sistem pendidikan hanya memberikan pilihan untuk diterapkan dalam bentuk kelompok dan tidak diterapkan secara individual. Padahal kurikulum yang efektif untuk meningkatkan kreativitas adalah kurikulum yang bersifat individualis, sebab setiap individu memiliki kreativitas yang berbeda-beda.

Masih banyak pula perspektif atau cara pandang orang tua dan guru yan masih keliru mengenai kreativitas (Runco, 2007). Kurang 
memandang kreativitas sebagai suatu bakat yang sama pentingnya dan sejajar dengan kecerdasan akademik. Akan tetapi kecedasan yang mempengaruhi keterampilan seperti kecerdasama analitis dan kecerdasan praktis (Sternberg, 2018) kurang begitu diperhatikan oleh orang tua.

Kebanyakan orang menganggap bahwa siswa yang unggul adalah siswa yan memiliki nilai bagus pada akademik, padahal yang sebenarnya harus ditekankan adalah pemikiran divergen dan kreatif yakni kemampuan untuk mengembangkan sesuatu yang baru ide dan untuk menemukan cara baru dalam penciptaan peluang (Antonio et al., 2014) yang dapat membantu siswa untuk dapat bersaing di dunia kerja di abad ke-21 ini (Abdul Hamid and Kamarudin, 2021). Oleh karena itu dalam meta analisis ini akan dibahas mengenai keterikatan antara pencapaian akademik (achievement) dan kreativitas siswa, apakah semakin tinggi kreativitas siswa akan mempengaruhi tingkat pencapaian akademik siswa atau justru sebaliknya.

\section{Siswa Berprestasi}

Stereotip yang berkembang saat ini di lingkungan sekolah adalah siswa cerdas akademik mengalahkan siswa yang kreatif. Hal ini selaras dengan yang disampaikan oleh Torrance (dalam Runco, 2007) bahwasannya guru lebih menyukai siswa yang tepat waktu, sopan dan siswa yang mengerjakan tugas dengan baik. Hal-hal yang tidaksesuaian dengan ketiga aspek tersebut dianggap sebagai masalah. Banyak karakteristik kreativitas yang bertentangan dengan stereotip siswa ideal, yakni berkenaan dengan otonomi, inkonvensionalitas, dan ketidaksesuaian. Melihat perpsepktif lintas budaya, Cropley dan Raina dan Raina (dalam Runco, 2007) menemukan bukti bahwa guru memandang perilaku dan ciri kepribadian anakanak kreatif secara tidak baik. Pandangan serupa juga dirasakan oleh orang tua.

Getzels dan Jackson (Runco, 2007) membandingkan siswa dengan IQ tinggi dan siswa yang sangat kreatif sebab diyakini bahawa siswa yang kreatif adalah siswa yang mendalami keilmuan tertentu (Haavold, 2020). Dapat disimpulkan bahwa kelompok ber-IQ tinggi terlihat lebih diharapkan, sedangkan kelompok kreativitas tinggi yang tidak unggul secara akademis kurang diminati oleh siswa. Mereka juga menguji hal tersebut kepada guru dan diketahui bahwa guru lebih menyukai siswa dengan keterampilan akademis daripada bakat siswa yang memiliki bakat kreatif. Berbeda dengan pernyataan Rhyammar dan Brolin yang menyatakan bahwa psikologis sosial yakni struktur sosial mempengaruhi kreativitas individu. Penilaian yang berpusat pada pencapaian nilai mata pelajaran menyebabkan berkurangnya kreativitas dalam pendidikan (Craft, 2004).

Situasi di sekolah kurang memfasilitasi perkembangan kreativitasnya. Diyakini bahwa lingkungan belajar yang menumbuhkan kreativitas adalah lingkungan belajar yang tidak terstruktur dan memungkinkan siswa untuk bebas berekspresi. Lingkungan yang seperti ini adalah lingkungan yang optimal untuk pertumbuhan kemampuan kreativitas individu. Sebab kreativitas bagi siswa berguna untuk membebaskan siswa mengekspresikan ide baru (Katz-Buonincontro et al., 2020).

Untuk mengetahui tingkat kreativitas anak, seringkali dilakukan tes untuk mengukurnya. Tes kreativitas ini menilai lima indeks penilaian yakni kefasihan, fleksibilitas, orisinalitas, elaborasi (jumlah ide yang ditambahkan untuk melengkapi ide dasar), dan skor verbal (Ma and Corter, 2019). Dalam tes tersebut anak diminta untuk menggambar sendiri berdasarkan judul yang sudah diberikan kepada mereka. Kemudian guru mengevaluasi anak-anak menggunakan skala penilaian perilaku Wallach dan Kogan. Tes ini meliputi perolehan fakta, kekhasan atau integrasi materi pelajaran, prestasi akademik, metode evaluasi, tunjangan dan pengakuan ekspresi artistik dan verbal, prioritas diberikan pada kesadaran diri, evaluasi teman sebaya hubungan, sistem pengambilan keputusan dan implementasi aturan, berbagai perilaku yang diperbolehkan di dalam kelas, dan berbagai 
perilaku kelompok yang diperbolehkan di dalam kelas. Hasilnya mengejutkan karena guru yang terlibat dalam penelitian ini tampaknya tidak memandang anak-anak kreatif sebagai penyesuaian yang buruk. Ada perbedaan jenis kelamin yang signifikan, yang tidak semuanya umum dalam penelitian tentang berpikir kreatif.

Menurut Runco dalam rangka untuk meningkatkan pemikiran kreatif, dalam proses belajar mengajar bahwa ekspresi non-verbal di kelas mungkin lebih dapat diterima oleh guru daripada kreativitas verbal. Namun tidak semua siswa dapat mengkomunikasikan kreativitas verbalnya, maka dari itu solusi yang tepat adalah pemberian tugas dengan pertanyaan terbuka yang memunculkan pemikiran kreatif siswa (Runco, 2007).

\section{Pandangan Pendidik mengenai Kreativitas}

Teori implisit tentang kreativitas anak yang harus dipahami oleh guru sangatlah penting karena mengarah langsung pada harapan dan ekspektasi, serta pengaruh tersebut sangat kuat terhadap perilaku siswa. Teori implisit sendiri sifatnya tidak perlu dipublikasikan atau diuji. Hal ini mengarah pada sesuatu keyakinan yang dipegang oleh orang tua dan guru, meliputi kecerdasan, kreativitas, kebijaksanaan, kreativitas artistik, ilmiah, dan sehari-hari.

Para orang tua dan guru sepakat bahwa anak-anak yang kreatif seringkali mudah beradaptasi, memiliki jiwa petualang, pintar, memiliki rasa ingin tau yang tinggi, berani, suka melamun, imajinatif, dan inventif. Sedangkan pandangan terhadap orang yang tidak kreatif yaitu suka menyendiri, berhati-hati, konvensional, mencari kesalahan, dan tidak berambisi. Melihat tanggapan ini menunjukkan bahwa pandangan lingkungan sosial (orang tua dan guru) dari kreativitas merupakan siswa yang ideal. Orang tua dan siswa meletakkan harapan yang tinggi pada siswa yang kreatif. Johnson (Runco, 2007) menyatakan bahwa guru dan orang tua mereka benar-benar membedakan antara aspek indikatif dan kontraindikasi dari kreativitas. Pada umumnya mereka memandang sifat kreatif sesuai dengan yang mereka inginkan dan harapkan.

\section{Perspektif Pendidikan tentang Kreativitas}

Menurut Runco dalam pengembangan kurikulum, jauh lebih mudah membuat kurikulum mata pelajaran seperti matematika daripada seni. Secara umum, kreativitas secara inheren bersifat individualistis (Wang and Nickerson, 2017). Namun sebagian besar sistem pendidikan yang ada, kurikulum diterapkan hanya untuk kelompok (Runco, 2007). Namun pernyataan ini dianggap kurang benar oleh Blunkett dan Smith (Craft, 2004), sebab dalam proses pengembangan konseptualisasi kreativitas harusnya diterapkan di seluruh kurikulum/ mata pelajaran dan tidak hanya terbatas pada mata pelajaran seni. Dalam artian sistem pendidikan hanya memberikan pilihan untuk diterapkan dalam bentuk kelompok dan tidak diterapkan secara individual. Padahal kurikulum yang efektif untuk meningkatkan kreativitas adalah kurikulum yang bersifat individualis, sebab setiap individu memiliki kreativitas yang berbeda-beda.

Pendidikan tradisional seringkali menghambat kreativitas siswa. Kreativitas mungkin membutuhkan pemikiran yang tidak konvensional. Sebagai contoh kebebasan secara otonom yang diberikan kepada siswa akan membuat guru merasa kesulitan. Menurut Raina (Runco, 2007) Siswa yang bebas itu bukanlah bagian dari apa yang dikenal sebagai profil siswa yang ideal. Secara sederhana, pandangan guru bahwasannya siswa yang ideal itu sopan, tepat waktu, dan hal-hal yang baik menurut pandangan guru.

Menurut Torrance (Runco, 2007) terdapat stigma yang melekat pada kreativitas. Pemikiran yang paling ekstrim tentang kreativitas adalah mencap orang sebagai orang yang "kontroversi/ jenius/gila", yang menyiratkan bahwa para jenius (atau genius yang kreatif) memiliki kecenderungan ke arah kegilaan. Sedangkan pemikiran lain kreativitas sebagai orang yang eksentrik dan aneh. Dalam artian, mereka memiliki perbedaan pemikiran antara 
kepribadian kreatif dan "siswa ideal". Jika ada stigma-stigma yang melekat pada kreativitas, sulit bagi pendidik (atau orang tua) untuk mendorong anak melakukan hal yang sesuai untuk mengembangkan kreativitas yang dimiliki.Seharusnya pendidik perlu melakukan tiga hal di bawah ini untuk mendukung dan meningkatkan kreativitas pada siswa:

1) Berikan kesempatan kepada anak untuk berlatih berpikir secara kreatif.

2) Menghargai upaya siswa untuk melakukan hal kreatif tersebut.

3) Contohkan perilaku kreatif itu sendiri

Beberapa hal di atas juga dapat dilakukan oleh orang tua agar dapat berdampak terhadap anak. Orang tua/ Guru juga perlu menghadirkan peluang, memperkuat, dan mencontohkan kreativitas. Kreativitas yang timbul dari praktik kolaboratif antara orang tua dan guru dapat mendukung hasil kreativitas yang baik (Craft, 2004). Pendidikan formal dan informal dapat mendukung bakat kreatif anak. Lebih khusus lagi, orang tua dan guru dapat memastikan bahwa anak-anak secara penuh dapat mengetahui dan mengembangkan potensi mereka. Menurut Runco keterbatasan dalam mengembangkan kreativitas pastilah ada, baik itu dari aspek genetik maupun lingkungan, tetapi yang paling penting adalah siswa/ anak dapat memenuhi potensi dan dapat tumbuh tanpa ada keterbatasan yang menghalangi perkembangan kreativitas itu sendiri. Pada dasarnya setiap siswa memiliki potensi untuk berekspresi secara kreatif (Runco, 2007) sebab pada dasarnya kreativitas merupakan hal yang unik dan setiap individu memiliki kapasitas yang berbeda-beda dari segi proses memunculkan ide baru hingga cara memproses produk (Haase et al., 2018; Walia, 2019). Berikut adalah pandangan dan perspektif mengenai kreativitas siswa dalam lingkungan pendidikan:

Pengembangan Kreativitas pada Sektor Pendidikan - Proses Pembelajaran yang Meningkatkan Kreativitas

Guru dapat mengembangkan kreativitas dengan berbagai cara, seperti yang dijelaskan di atas mereka dapat memberikan penghargaan positif tanpa syarat. Namun disamping itu dalam rangka meningkatkan kreativitas individu, guru dapat mencontohkan kreativitas dengan berbagai cara. Salah satunya adalah pendidik memberikan contoh yang baik kepada muridnya, sebab banyak siswa meniru gurunya. Guru harus berfikir secara kreatif pula agar menjadi contoh yang baik, yakni dengan cara berpikir secara berbeda, memecahkan masalah dengan cara yang orisinal, menunjukkan fleksibilitas, namun semua hal yang dilakukan harus dengan aturan yang sesuai atau bijak dalam melakukannya.

Simonton (dalam Runco, 2007) menyarankan agar guru dan siswanya secara optimal hanya memiliki minat dan pendekatan yang sama. Karena jika terlalu mirip, siswa hanya meniru dan mengikuti jejak sang mentor. Jika mereka terlalu berbeda, siswa mungkin tidak akan mendapatkan keuntungan dari keahlian dan koneksi mentor. Karakterisasi ini hanya dapat diterapkan secara langsung ke hubungan mentor selama masa dewasa (misalnya, perguruan tinggi, sekolah pascasarjana, posisi postdoktoral).

Pendidik perlu melakukan dan menghindari hal-hal tertentu dalam proses mendidik. Kreativitas didukung dengan menghilangkan hambatan serta dengan menemukan dukungan dan dorongan. Pendidik tentunya harus menghindari squelchers atau hal-hal yang dapat menghambat kreativitas. Pendidik perlu membiarkan kreativitas tetapi juga mendukung perilaku yang diterima secara sosial. Oleh karena itu, salah satu hal terpenting untuk kreativitas adalah kebijaksanaan bukan pengabaian yang liar, tetapi pengekspresian diri secara bijaksana. Pengekspresian tersebut akan mendorong untuk meningkatkan rasa kaingintahuan yang akan semakin mengasah kreativtas seseorang (Schutte and Malouff, 2020).

Pendidik juga harus menghindari penekanan motivasi eskstrinsik karena siswa akan tergantung terhadap hal tersebut. Sebab motivasi intrinsik memungkinkan siswa untuk mengikuti minatnya sendiri atau berfikir dan berekspresi seacara ekspresif tanpa khawatir akan 
menyenangkan guru. Dalam artian pendidikan yang dilakukan tidak berpusat pada guru tetapi berpusat pada anak. Sehingga kreativitas diartikan sebagai suatu bentuk "ekspresi diri" secara penuh yang dimiliki oleh anak tetapi dengan mendapatkan masukan dari pengajar (Craft, 2004). Begitu pula dengan memfasilitasi siswa dalam kegiatan ekstrakurikuler adalah salah satu untuk meningkatkan kreativitas siswa (Farsimadan et al., 2015).

Beberapa hal yang dibahas adalah berkaitan dengan motivasi dan melibatkan siswa dalam aktivitas dan lingkungan sehari-hari yang menumbuhkan antusiasme (Conner and Silvia, 2015), namun dalam Runco kurang membahas mengenai spiritual dengan proses pengembangan kreativitas. Craft berpendapat bahwa karakteristik pedagogi kreatif yang diamati di ruang kelas serupa dengan beberapa karakteristik spiritualitas. Pada pendekatan spiritual memfokuskan pada pendidikan sebagai pengembangan pribadi dan mengembangkan siswa sebagai manusia yang seutuhnya (Craft, 2004).

Jadi Guru atau pengajar dapat mengantisipasi atau melakukan usaha preventif dengan memberikan motivasi ekstrinsik secukupnya (pujian, hadiah, dll) agar kreativitas yang muncul dikarenakan motivasi intrinsik. Tidak salah memberikan imbalan, tetapi tidak berlebihan agar siswa tidak terfokus pada imbalan tetapi fokus terhadap minatnya sendiri (Runco, 2007).

\section{Hubungan Achievement (Pencapaian Akademik) dengan Kreativitas Siswa}

Lee dan Seo (dalam Runco, 2007) menemukan bahwa guru yang memiliki banyak pengalaman terkadang memiliki pandangan bias tentang kreativitas. Mereka menemukan bahwa guru menekankan pada aspek kognitif saat memandang kreativitas pada seseorang dan cenderung menurunkan aspek pribadi dan lingkungan. Padahal aspek pribadi dalam penelitian ini sangat penting, sebab meliputi motivasi instrinsik, minat dan emosi.
Bias / kesalahan cara pandang guru ini sangat bergantung terhadap anak kreatif dapat mempengaruhi perlakuan mereka kepada siswa.

Sebab siswa menjadi anak yang kreatif, ketika mereka berada di lingkungan yang aman dan permisif. Sedangkan orang tua di wilayah asia, baik orang tua maupun guru, tampaknya cenderung memandang keterampilan sebagai cerminan dari kerja keras dibandingkan bakat bawaan. Perspektif ini menuntun mereka untuk mendorong kerja keras dan peningkatan usaha.

Selain itu menurut Lee dan Seo (dalam Runco, 2007) menganggap bahwa guru mendefinisikan kreativitas dalam kaitannya dengan produk atau portofolio, namun kreativitas tidak hanya dipandang hanya dari produknya. Di dalamnya menyangkut proses kreatif yang perlu juga menjadi perhatian. Jika dilihat dari urgensinya sangat diperlu berinvestasi dalam potensi kreatif karena yang menjadi pembeda orang biasa dengan orang sukses adalah etos kerja dan ketekunan mereka. Mereka menginvestasikan waktu mereka untuk mempelajari hal-hal yang mereka minati atau untuk keterampilan tertentu (seni, bermain musik,dll) (Runco, 2007). Terjadi banyak sekali bias antara pencapaian akademik atau aspek kognitif terhadap kreativitas siswa, sehingga peneliti ingin meneliti sejauh mana penelitian terkait kedua variabel tersebut. Keterkaitan kedua variabel dalam rangka untuk melihat sejauh mana kreativitas mempengaruhi aspek kognitif.

\section{METODE PENELITIAN}

Penelitian ini menggunakan desain Meta Analisis. Meta analisis secara sederhana dapat diartikan sebagai analisis atas analisis. Sebagai penelitian, meta analisis merupakan kajian atas sejumlah hasil penelitian dalam masalah yang sejenis. Instrumen dalam penelitian ini menggunakan Human Instrument.

Teknik pengumpulan data akan menggunakan teknik dokumentasi. Populasi dalam penelitian ini adalah semua dokumen tertulis yang diunduh melalui Science Direct, 
Elsevier, maupun Google Scholar mengenai Achievement dan Kreativitas. Rentang penelitian yang terkait adalah mulai tahun 2011 sampai dengan 2020. Dokumen tertulis tersebut berupa: artikel jurnal, dan laporan penelitian. Sampel penelitian yang diambil menggunakan teknik Purposive Sampling. Hal ini dikarenakan data atau informasi yang ingin diperoleh dari sampel ditentukan berdasarkan kesesuaiannya dengan tema penelitian ini. Analisis data yang digunakan adalah analisis data kuantitatif dengan prosentase dan analisis data kualitatif untuk data-data hasil kajian naratif terhadap penelitian-penelitian yang ditemui.

Terdapat tambahan variabel moderasi yakni rentang usia, melihat seberapa berpengaruh usia terhadap kreativitas seseorang. Hipotesis yang disusun adalah dengan $\mathrm{HO}=$ Tidak ada pengaruh antara Kreativitas dan Nilai Akademik dengan
$\mathrm{H} 1$ = Ada pengaruh antara kreativitas dan nilai akademik. $\mathrm{P}>0.05 \mathrm{H} 0$ gagal ditolak dan $\mathrm{P}<$ $0.05 \mathrm{H} 0$ ditolak

\section{HASIL DAN PEMBAHASAN}

\section{a. Hasil}

Penelitian-penelitian tentang hubungan atau korelasi variabel kreativitas dan achievement atau penilaian akademik yang didapatkan adalah sebanyak 11 penelitian. Penelitian-penelitian itu diperoleh dari berbagai sumber, yaitu: artikel (hasil penelitian) dalam jurnal hasil penelitian Secara umum data tersebut didapatkan dengan mengunduh dari internet melalui alamat website science direct dan google scholar. 11 penelitian yang digunakan menggunakan korelasi dan kemudian mendapatkan nilai $r$ dari setiap penelitian. Berikut adalah tabel penelitian yang dilakukan pengujian meta analisis:

\begin{tabular}{|l|l|c|c|c|}
\hline No. & Peneliti & Korelasi (Nilai r) & Jumlah Sampel & Rentang Usia \\
\hline 1 & (Ghasemi et al., 2011) & 0.31 & 365 & $15-18$ \\
\hline 2 & (Nami et al., 2014) & 0.769 & 242 & $15-18$ \\
\hline 3 & (Balgiu and Adîr, 2014) & 0.24 & 86 & $22-23$ \\
\hline 4 & (Antonio et al., 2014b) & 0.074 & 287 & $21-23$ \\
\hline 5 & (Gajda, 2016) & 0.16 & 1106 & $7-18$ \\
\hline 6 & (Arya and Maurya, 2016) & 0.19 & 300 & $12-16$ \\
\hline 7 & (Mohammadi et al., 2016) & 0.025 & 303 & $21-23$ \\
\hline 8 & (Rani, 2013) & 0.04 & 640 & $15-18$ \\
\hline 9 & (Kaboodi and Jiar, 2012) & 0.36 & 272 & $15-16$ \\
\hline 10 & (Berlin et al., 2016) & 0.032 & 99 & $7-13$ \\
\hline 11 & (Sarwandianto et al., & 0.729 & 63 & \multirow{2}{*}{} \\
\hline
\end{tabular}

Hasil analisis pada aplikasi Jamovi menunjukkan hasil sebagai berikut :

Random-Effects Model ( $\mathrm{n}=11)$

\begin{tabular}{lllllll}
\hline & Estimate & Se & Z & P & CI Lower Bound & CI Upper Bound \\
\hline Intercept & 0.305 & 0.103 & 2.96 & 0.003 & 0.103 & 0.507 \\
& $\cdot$ & $\cdot$ & $\cdot$ & $\cdot$ & $\cdot$ & $\cdot$ \\
\hline
\end{tabular}

Note. Tau² Estimator: Restricted Maximum-Likelihood 
Heterogeneity Statistics

\begin{tabular}{lllccccc}
\hline Tau & Tau $^{2}$ & $\mathbf{I}^{2}$ & $\mathbf{H}^{2}$ & $\mathbf{R}^{2}$ & $\mathbf{d f}$ & $\mathbf{Q}$ & $\mathbf{p}$ \\
\hline 0.333 & $0.1111(\mathrm{SE}=0.0521)$ & $97.22 \%$ & 36.018 &. & 0.000 & 237.911 & $<.001$ \\
\hline
\end{tabular}

Model Fit Statistics and Information Criteria

\begin{tabular}{llcccc}
\hline & $\begin{array}{l}\text { log- } \\
\text { likelihood }\end{array}$ & Deviance & AIC & BIC & AICc \\
\hline $\begin{array}{l}\text { Maximum-Likelihood } \\
\begin{array}{l}\text { Restricted Maximum- } \\
\text { Likelihood }\end{array}\end{array}$ & -3.388 & 47.109 & 10.776 & 11.572 & 12.276 \\
\hline
\end{tabular}

\section{a. Heterogenitas}

Tampaknya korelasi sebenarnya bervariasi antara studi. Statistik $\mathrm{I}^{2}$ menunjukkan proporsi varians dalam efek yang diamati disebabkan kesalahan pengambilan sampel. Dalam contoh ini, $\mathrm{I}^{2}=97,22 \%$. Jika dilihat dari nilainya lebih dari $50 \%$ dapat dikatakan bahwa data sudah memenuhi kriteria penelitian meta analisis yakni data sudah heterogen. Dapat dikatakan sudah memenuhi asumsi meta analisis.

\section{b. Effect size}

Meta-analisis dilakukan dengan jumlah jurnal sebanyak 11 jurnal. Koefisien korelasi diubah menjadi koefisien korelasi Fisher Z untuk analisis dan ditransformasi balik untuk pelaporan. Korelasi rata-rata antara variabelvariabel di atas adalah $\mathrm{r}=0.305,(\mathrm{p}=0.003$, dengan tingkat kesalahan 95\% $[0,1<0,51])$. Effect size tersebut arahnya positif, sehingga dapat dikatakan terdapat korelasi, namun korelasinya lemah sebab untuk nilai 0.305 terletak pada range $0,20-0,399$ dapat dikatakan hubungan korelasinya lemah.

\section{c. Penghitungan p value}

Dilakukan pula Uji Q Cochran untuk mengetahui variasi dalam korelasi yang diamati untuk kesalahan pengambilan sampel $(\mathrm{Q} \sim(\mathrm{df}=10) \sim=237.91, \mathrm{p}=<.001$. Dari hasil di atas bahwasannya $\mathrm{p}$ value $<0,05$ dapat disimpulkan bahwa hasil meta analisis menolak hipotesis nol (H0) sehingga ada pengaruh kreativitas terhadap penilaian akademik namun jika dilihat dari nilainya pengaruh tersebut tidaklah signifikan.

Jadi dapat disimpulkan tingkat kesalahan atau kredibilitas 95\% dengan kesimpulan korelasi negative terletak pada $\mathrm{r}=-0,38$ dan korelasi positif terletak pada $=0,99$. Berikut adalah sebaran datanya : 


\section{Marginal Posterior Density Plots $(\tau)$}

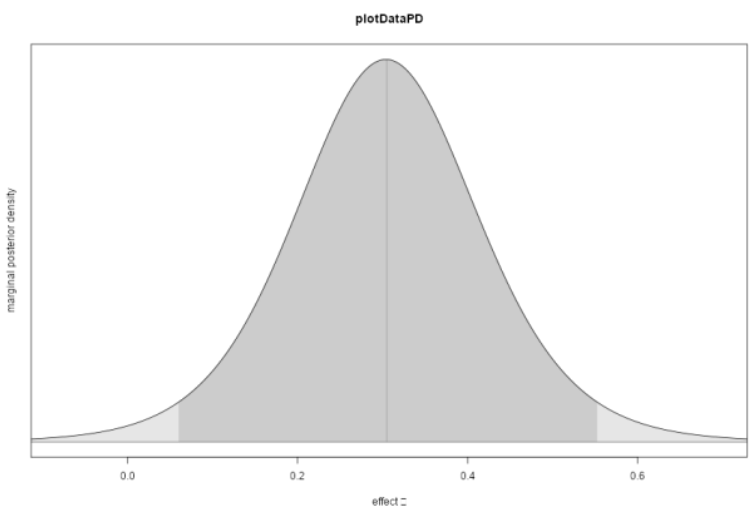

Marginal Posterior Density Plots $(\mu)$

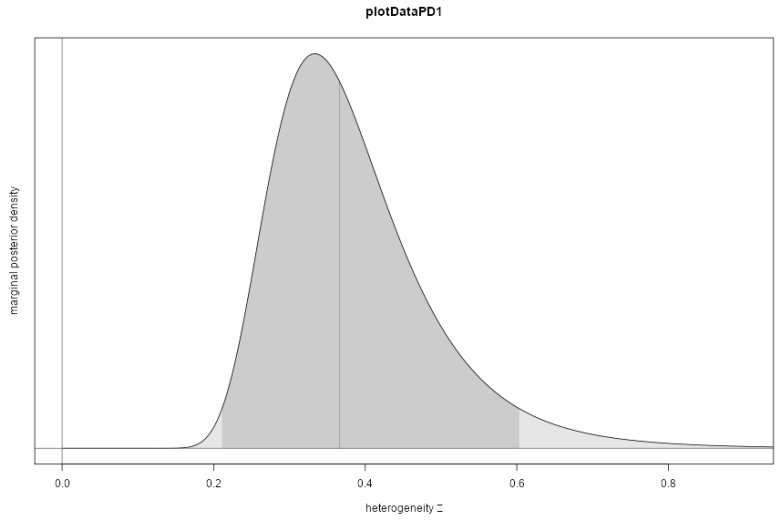

Marginal Posterior Density Plot $(\mu)$ menunjukkan heterogenitas pada data yang ditampilkan, hal ini menunjukkan bahwa sebaran data berada di bawah rata-rata (condong ke kiri) menunjukkan bahwa data yang diperoleh banyak dibawah rata-rata dan condong ke arah korelasi yang lemah antara kreativitas dan achievement.

\section{Forest Plot}

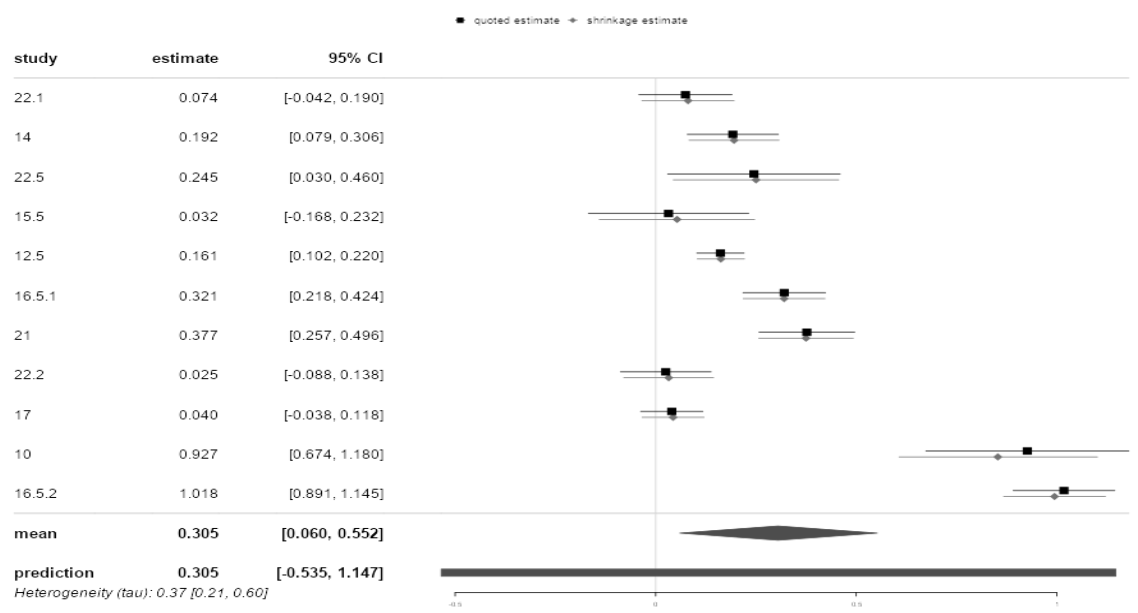


Persebaran datanya adalah seperti data di atas dengan tingkat kesalahan 95\%, diketahui rata-rata data di atas adalah 0.305 dengan skor simpangan terendah 0.060 dan tertinggi adalah 0.552. Dapat disimpulkan bahwa korelasi kedua b. Pembahasan

Dari hasil meta anaisis di atas dapat dikatakan bahwa korelasi antara kreativitas dan achievement namun tidaklah signifikan. Pada hasil penelitian nilai hubungan (r) yang tinggi, penelitian dilakukan pada siswa dengan metode yang tepat dan tidak pada penugasan yang berhubungan dengan kemampuan memori dan kognitif, sehingga hubungan keduanya masih dapat dikatakan signifikan. Namun korelasinya terbilang lemah disebabkan karena kreativitas siswa tidak begitu berpengaruh pada pencapaian nilai akademik siswa. Siswa yang memiliki nilai bagus secara akademik belum tentu termasuk siswa yang kreatif begitu pula sebaiknya. Tidak perbedaan ditemukan antara aspek-aspek yang diteliti dalam memprediksi prestasi akademik. Karena sebagian besar pengujian yang dilakukan di sekolah atau bersifat akademis mendukung memori dan kemampuan kognitif. Sedangkan kreativitas sering dinilai berlebihan sampai pada pengaruhnya dalam meningkatkan akademik siswa (Bentley, 1966).

Ada beberapa faktor yang mempengaruhi ditentukan dalam meta analisis ini, salah satu variabel yang memoderasi dari penelitian ini adalah faktor usia. Dapat dikatakan bahwa achievement akan berkorelasi kuat dengan kreativitas atau dapat dikatakan kreativitas sangat mempengaruh achievement pada masa kanak-kanak. Seiring perkembangan usia kreativitas kurang mempengaruhi pencapaian akademik pada seseorang. Sejalan dengan hal itu penelitian yang dilakukan di Polandia menunjukkan bahwa karakteristik proses pengajaran pada berbagai tahapan pendidikan menunjukkan bahwa hubungan antara prestasi sekolah dan kreativitas akan lebih kuat pada anak-anak yang lebih kecil, dan akan melemah seiring dengan bertambahnya usia siswa. Dalam Pada tahap awal sekolah dasar, kurikulum variabel tersebut memiliki korelasi yang rendah. Garis menunjukkan tiap data. Jadi, plot yang data studi 3,4 dan 10 dapat mengurangi kekuatan dari effect size, sedangkan data yang lainnya mendukung kekuatan dari effect size itu sendiri.

Polandia sebagian besar terdiri atas kegiatankegiatan bermain, yang tidak membatasi aktivitas spontan anak. Selama bertahun-tahun, siswa dihadapkan dengan persyaratan yang lebih serius dan ruang untuk kegiatan kreatif relatif terbatas (Gajda, 2016).

Kreativitas kurang berkorelasi pada peningkatan nilai akademik siswa pada jenjang pendidikan yang lebih tinggi dalam artian dari usia sekolah menengah pertama sampai pada jenjang pendidikan yang lebih tinggi. Hal ini dikarenakan tuntutan pendidikan yang lamakelamaan akan semakin berat seiring dengan semakin tingginya jenjang pendidikan dan semain sedikitnya kegiatan kreatif dalam jenjang pendidikan tinggi yang menyebabkan kreativitas berkurang pada masa jenjang pendidikan yang lebih tinggi. Kreativitas di bidang pendidikan berhubungan dengan cara penyelesaian masalah dan pengambilan kesimpulan serta pengajaran yang membebaskan siswa mengekspresikan ide baru (Katz-Buonincontro et al., 2020). Lingkungan pembelajaran yang membebaskan siswa untuk berfikir lebih kreatif dan guru dengan metode mengajar yang kreatif merupakan definisi kreativitas yang sesungguhnya dalam setting pendidikan. Kreativitas dapat berguna pada kehidupan di masa yang akan datang sebab orang-orang memerlukan pemikiran kreatif untuk bertahan hidup di abad kedua puluh satu, hal ini telah dibuktikan dalam studi pendidikan (Akyıldız and Çelik, 2020).

\section{KESIMPULAN}

Kreativitas sering dikaitkan dengan kecerdasan dan kemampuan kognitif, padahal jika kita menelisik dan meneliti lebih jauh hal ini merupakan hal yang salah. Kreativitas berbeda dengan intelegensi atau kecerdasan siswa. 
Sehingga tidak dapat disamakan siswa yang kreatif dengan siswa yang memiliki nilai akademik yang baik. Siswa kreatif belum tentu siswa yang memiliki achievement atau pencapaian akademik yang baik, begitu pula sebaliknya. Dibuktikan dengan penelitian meta analisis yang dilakukan bahwasannya tidak ada pengaruh yang signifikan kreativitas terhadap pencapaian akademik. Kreativitas di bidang pendidikan berhubungan dengan pemecahan masalah, pencarian solusi dan membebaskan individu untuk mengekspresikan ide tidak berkorelasi dengan pencapaian nilai dalam akademik.

\section{REFERENSI}

Abdul Hamid, N.H., Kamarudin, N., 2021. Assessing Students' Mathematics Achievement and Mathematical Creativity using Mathematical Creative Approach: A Quasi-Experimental Research. Asian J. Univ. Educ. 17, 100. https://doi.org/10.24191/ajue.v17i2.133 99

Akyıldı, S.T., Çelik, V., 2020. Thinking outside the box: Turkish EFL teachers' perceptions of creativity. Think. Ski. Creat. 36, 100649. https://doi.org/10.1016/j.tsc.2020.10064 9

Antonio, T., Lanawati, S., Wiriana, T.A., Christina, L., 2014. Correlations Creativity, Intelligence, Personality, and Entrepreneurship Achievement. Procedia - Soc. Behav. Sci. 115, 251257.

https://doi.org/10.1016/j.sbspro.2014.02. 433

Arya, M., Maurya, S.P., 2016. Relationship between Creativity, Intelligence and Academic Achievement among School Going Children. Stud. Home Community Sci. 10, 1-7. https://doi.org/10.1080/09737189.2016. 11885359

Balgiu, B.A., Adîr, V., 2014. Creativity Tasks and Academic Achievement. A Study on Romanian Politehnica Undergraduate Students. Procedia - Soc. Behav. Sci.
116 , 924-928. https://doi.org/10.1016/j.sbspro.2014.01. 321

Bentley, J.C., 1966. Creativity and Academic Achievement. J. Educ. Res. 59, 269272. https://doi.org/10.1080/00220671.1966. 10883353

Berlin, N., Tavani, J.-L., Beasançon, M., 2016. An exploratory study of creativity, personality and schooling achievement. Educ. Econ. 24, 536-556. https://doi.org/10.1080/09645292.2015. 1117580

Conner, T.S., Silvia, P.J., 2015. Creative days: A daily diary study of emotion, personality, and everyday creativity. Psychol. Aesthet. Creat. Arts 9, 463470. https://doi.org/10.1037/aca0000022

Craft, A. (Ed.), 2004. Creativity in education, reprinted. ed. Continuum, London.

Farsimadan, E., Poorgholami, F., Safari, H., Ahmadi Gharacheh, A.M., 2015. An Investigation into the Effects of Curriculum Enrichment on Creativity and Achievement Motivation of Gifted students in Public Schools. Mediterr. J. Soc.

Sci. https://doi.org/10.5901/mjss.2015.v6n6s $6 \mathrm{p} 297$

Gajda, A., 2016. The relationship between school achievement and creativity at different educational stages. Think. Ski. Creat. 19, 246-259. https://doi.org/10.1016/j.tsc.2015.12.004

Ghasemi, F., Rastegar, A., Jahromi, R.G., Marvdashti, R.R., 2011. The relationship between creativity and achievement motivation with high school students' entrepreneurship. Procedia - Soc. Behav. Sci. 30, 12911296.

https://doi.org/10.1016/j.sbspro.2011.10. 250

Haase, J., Hoff, E.V., Hanel, P.H.P., Innes-Ker, A., 2018. A Meta-Analysis of the Relation between Creative Self-Efficacy and Different Creativity Measurements. Creat. Res. J. 30, 1-16. 
https://doi.org/10.1080/10400419.2018. 1411436

Haavold, P.Ø., 2020. An Investigation of the Relationship between Age, Achievement, and Creativity in Mathematics. J. Creat. Behav. 54, 555566. https://doi.org/10.1002/jocb.390

Kaboodi, M., Jiar, Y.K., 2012. Creativity and Academic Achievement: Comparison between Cognitive and Trait Creativity 4.

Katz-Buonincontro, J., Perignat, E., Hass, R.W., 2020. Conflicted epistemic beliefs about teaching for creativity. Think. Ski. Creat. 36, 100651. https://doi.org/10.1016/j.tsc.2020.10065 1

Ma, Y., Corter, J.E., 2019. The effect of manipulating group task orientation and support for innovation on collaborative creativity in an educational setting. Think. Ski. Creat. 33, 100587. https://doi.org/10.1016/j.tsc.2019.10058 7

Mohammadi, S.D., Moslemi, Z., Ghomi, M., 2016. The relationship between critical thinking skills with creativity and academic achievement among students in Qom University of Medical Sciences. Educ. Sci. Psychol. Dep. Hum. Sci. Fac. Arak Univ. Arak Iran.

Nami, Y., Marsooli, H., Ashouri, M., 2014. The Relationship between Creativity and Academic Achievement. Procedia - Soc. Behav. Sci. 114, 36-39. https://doi.org/10.1016/j.sbspro.2013.12. 652
Rani, G., 2013. Relationship of Creativity and Achievement Motivation of Senior Secondary Students. Res. Educ. 2, 6.

Runco, M.A., 2007. Creativity: theories and themes: research, development, and practice. Elsevier Academic Press, Amsterdam ; Boston.

Sarwandianto, A., Alamsyah, N., Wulan, R., Awaludin, A.A.R., 2020. Relationship between creativity and learning style and mathematics learning achievement of elementary school students. Presented at the 28TH RUSSIAN CONFERENCE ON MATHEMATICAL MODELLING IN NATURAL SCIENCES, Perm, Russia, p. 060027. https://doi.org/10.1063/5.0001018

Schutte, N.S., Malouff, J.M., 2020. A Meta-Analysis of the Relationship between Curiosity and Creativity. J. Creat. Behav. 54, 940-947. https://doi.org/10.1002/jocb.421

Sternberg, R.J., 2018. A triangular theory of creativity. Psychol. Aesthet. Creat. Arts 12, 50-67. https://doi.org/10.1037/aca0000095

Walia, C., 2019. A Dynamic Definition of Creativity. Creat. Res. J. 31, 237-247. https://doi.org/10.1080/10400419.2019. 1641787

Wang, K., Nickerson, J.V., 2017. A literature review on individual creativity support systems. Comput. Hum. Behav. 74, 139-151.

https://doi.org/10.1016/j.chb.2017.04.03 5 